\title{
LIGASURE HAEMORRHOIDECTOMY IN COMPARISON WITH CONVENTIONAL HAEMORRHOIDECTOMY- A CASE STUDY ON 100 PATIENTS
}

\author{
Gaurav Wadhawan' 1 B. M. Soni', K. C. Vyas ${ }^{3}$
}

${ }_{1}^{1}$ Associate Professor, Department of General Surgery, Pacific Medical College and Hospital, Udaipur, Rajasthan, India.

${ }^{2}$ Associate Professor, Department of General Surgery, Pacific Medical College and Hospital, Udaipur, Rajasthan, India.

3 Professor and HOD, Department of General Surgery, Pacific Medical College and Hospital, Udaipur, Rajasthan, India.

\section{ABSTRACT}

\section{BACKGROUND}

For the grade III and IV internal haemorrhoids surgery is the only treatment option and the conventional haemorrhoidectomy in them is an unvaried approach associated with significant morbidity and a prolonged recuperation, but it is a very popular method of treatment modality due to its cost effectiveness and significant long-term outcome. The Ligasure tissue sealing device is an alternative technique used in haemorrhoidectomy that has shown to produce favourable results.

The objective of the study was to compare the effectiveness of the Ligasure tissue sealing device in comparison with conventional haemorrhoidectomy.

\section{MATERIALS AND METHODS}

100 consecutive patients of third and fourth degree internal haemorrhoids were grouped into either the Ligasure haemorrhoidectomy (50 patients) or conventional haemorrhoidectomy (50 patients) who visited Pacific Medical College and Hospital Surgery Department for the period from January 2014 to December 2016. They were evaluated on the criteria of below mentioned main outcomes: Bleeding, post-operative pain (measured on a visual analogue scale), mean operative time, hospital stay, early and late complications, rate of wound healing and recovery time of work. Patients were followed up for 12 months (range 12 - 24). The sample size required was taken for convenience.

\section{RESULTS}

Hundred patients grouped into two prospective, randomised, controlled trial of fifty each for Ligasure and conventional haemorrhoid surgery. The result was compared amongst the two groups and tabulated. In comparison to conventional haemorrhoidectomy, Ligasure haemorrhoidectomy had an edge over with shorter operating time, less intraoperative and postoperative blood loss, less pain and postoperative complications including urinary retention, haemorrhage and wound breakdown.

\section{CONCLUSION}

Ligasure haemorrhoidectomy has proved to be superior to conventional diathermy haemorrhoidectomy. Ligasure is an effective tool when a large tissue clearance is required. With Ligasure we achieve good haemostasis, causing a wafer-thin seal of the tissue and blood vessels, sutureless surgery and the external components of haemorrhoids can also be treated together. This study concludes its use as the treatment of preference for grade III and IV haemorrhoids as a day-care procedure, even if the procedure is costlier than the conventional haemorrhoidectomy.

\section{KEY WORDS}

Haemorrhoidectomy, Ligasure, Diathermy, Haemorrhoids.

HOW TO CITE THIS ARTICLE: Wadhawan G, Soni BM, Vyas KC. Ligasure haemorrhoidectomy in comparison with conventional haemorrhoidectomy- a case study on 100 patients. J. Evolution Med. Dent. Sci. 2018;7(37):4091-4094, DOI: $10.14260 /$ jemds $/ 2018 / 915$

\section{BACKGROUND}

Haemorrhoids are outcome of rich lifestyle and focussed on modern fast foods along with sedentary lifestyle resulting in constipation and straining at defecation. For first and second degree haemorrhoids conservative treatment is usually successful, but the third and fourth degree haemorrhoids require surgical intervention.(1) The therapeutic option includes rubber band ligation, sclerotherapy, cryotherapy and photocoagulation. However, haemorrhoidectomy of the Milligan and Morgan(2) variety (Open haemorrhoidectomy) or

'Financial or Other Competing Interest': None.

Submission 11-07-2018, Peer Review 27-08-2018,

Acceptance 03-09-2018, Published 10-09-2018.

Corresponding Author:

Dr. Gaurav Wadhawan,

\#3, Dhabai Complex,N. B. Nagar, Bedwas,

Udaipur-313024, Rajasthan, India.

E-mail: gauravwadhawan9@gmail.com

DOI: $10.14260 /$ jemds $/ 2018 / 915$ the gold standard. Recently, stapled haemorrhoidectomy (MIPH) for prolapsed haemorrhoids has come into trend, but has not gained popularity because of technical and monetary reasons.(4) Modified electrosurgical device, the Ligasure, has become available from the last decade as a vessel sealing electrosurgical device system for the treatment of haemorrhoids and has gained a vast acceptance and good popularity. This system is an improved version of bipolar diathermy device with additional advantage of achieving haemostasis by its vessel sealing effect upto $7 \mathrm{~mm}$ in diameter and very little lateral spread of current or heat confined to $2 \mathrm{~mm}$ over the operative field.

\section{Objectives}

1. To see the effectiveness of Ligasure as an operative tool in terms of use, postoperative pain and complications, wound healing rate, hospital stay, mean operative time and time off work. 
2. To compare the results with conventional haemorrhoidectomy on patients of Udaipur city, Rajasthan, attending Pacific Medical College and Hospital.

\section{MATERIALS AND METHODS}

This prospective, randomised, controlled study was carried out in the Department of General Surgery, Pacific Medical College and Hospital, Udaipur, Rajasthan in the year from January 2014 - December 2016. The study included 100 patients who were regularly attending the hospital for the treatment and had given consent of participation in the study and of symptomatic grade III and IV haemorrhoids. The patients were equally grouped into two; Ligasure haemorrhoidectomy (50 patients) and the conventional haemorrhoidectomy either open (Milligan and Morgan) or the closed (Ferguson) technique (50 patients) using sealed envelopes. The randomisation was performed using sequentially numbered envelopes preoperatively in a nonconsecutive manner. Excluded were patients with liver diseases like cirrhosis and of bleeding diathesis, combined procedure with fissures or fistulae, or history of allergy to any particular medication. The sample size required was taken for convenience.

The patients were investigated, pre-anaesthetic checkups were done and if found fit were hospitalised a day before surgery. They were operated under caudal block or spinal anaesthesia and few under IV sedation. The surgery was done in lithotomy position. The initial steps in both the Ligasure and conventional haemorrhoidectomy were same and included-

1. Anal dilatation or sphincter stretching that is Lord's dilatation upto 4 fingers.

2. Delivery of haemorrhoidal mass with the help of Babcock's forceps.

In the conventional method, the haemorrhoids were dissected from the internal sphincter by diathermy and the vascular pedicle was ligated and cut. The vascular pedicle of the haemorrhoids was sealed by Ligasure without transfixation and excised with the help of Ligasure itself. The procedure was repeated for each quadrant and loose anal pack was put. The patients were asked to take hot Sitz bath on the next day of surgery; laxatives were given for a month after surgery. The patients were asked to grade the severity of pain on 0 - 10 Visual Analogue Scale (VAS) on the evening of surgery- Day 0, Day 1 and Day 7 on follow-up. The wound healing assessment was done according to a five-point scale from Grade 1: Sloughy, Grade 2: no granulation, Grade 3: Granulating, Grade 4: Epithelializing, Grade 5: Completely Epithelialized. Blood loss was assessed by the number of soaked gauzes and the operative time was recorded by an operation theatre staff.

All the results were recorded on the Microsoft Excel sheet and were analysed by Statistical Package for the Social Sciences 20.0 for Windows (IBM Corp; Armonk, NY, USA) Software. All the results were calculated as percentages, mean and standard deviation, or median and range. Continuous data were analysed by using independent sample t-test. The $p$-value was considered significant if it is less than 0.05. Mean values were compared using Chi-square test.

\section{RESULTS}

The two groups were compared for age. Mean age for conventional being 42 years and 37 years for Ligasure haemorrhoidectomy. The youngest being 22 years old and 67 years the oldest in the study. The sex ratio showed a strong male predominance 41:9 in conventional to 33:17 in Ligasure group. The mean operative time was more in favour of Ligasure haemorrhoidectomy with average $12.4 \pm 4.6$ minutes to $33.2 \pm 6.5$ minutes for conventional haemorrhoidectomy. Ligasure method is significantly fast ( $\mathrm{p}$ $<0.05$ ). The patients operated via Ligasure method were discharged much earlier as compared to conventional method. $1.2 \pm 0.6$ days was the mean stay for Ligasure haemorrhoidectomy patients as compared to $3.4 \pm 1.12$ days for conventional haemorrhoidectomy $(\mathrm{p}<0.001)$ (Table 1$)$.

The amount of intraoperative blood loss measured by weighing the gauze before and after being soaked with blood was significantly higher in the conventional method $22.4 \pm$ $6.12 \mathrm{~mL}(20-30 \mathrm{~mL})$ in comparison to Ligasure method $1.2 \pm$ $1.0 \mathrm{~mL}(0-5 \mathrm{~mL})(\mathrm{p}=0.006)$.

Post-operative pain in the immediate postoperative scale did not show much difference between the two groups. The VAS pain score was $4.1 \pm 0.8$ for conventional surgery in comparison to $3.3 \pm 0.8$ in Ligasure surgery $(p=.044)$. There was a decreased need of analgesic drugs in Ligasure method after one week, $1.8 \pm 0.6$ in conventional surgery as compared to $1.2 \pm 0.5(\mathrm{p}=.234)$, but the Ligasure patients were close to baseline (no pain at all ) at the end of 10 days earlier than conventional patients who still had some pain stigmas to report. Patients operated via Ligasure method returned to work earlier $4.23 \pm 1.62$ days ( 5 to 7 days) after operation as compared to conventional method $8.6 \pm 4.32$ (10 to 14 days) $(\mathrm{p}<0.05)$.

Ligasure haemorrhoidectomy was superior significantly in terms of wound healing, almost $96 \%$ of wounds had completely epithelialized in 4 weeks as compared to $75 \%$ in the conventional group ( $\mathrm{p}=0.0001$ ).

The overall complication between the two groups was 7:50 (14\%) for conventional haemorrhoidectomy in comparison to 2:50 (4\%) for Ligasure haemorrhoidectomy. Bleeding was the most common post-operative complication in both the groups, 5:50 (10\%) patients had bleeding in conventional method and 2:50 (4\%) patients had bleeding in Ligasure method $p=0.15$. One patient developed anal stenosis in Grade IV haemorrhoids operated by open haemorrhoidectomy, which later required repeated anal dilatations and only one of the conventionally operated patients had to undergo re-surgery. None of the patients had any incontinence or urinary retention complaint postoperatively and there was no reported deaths outcome of haemorrhoids surgery in both the groups (Fig. 1). 


\begin{tabular}{|c|c|c|}
\hline Details & Conventional Haemorrhoidectomy (n= 50) & Ligasure Haemorrhoidectomy (n= 50) \\
\hline Sex Ratio Male: Female & $41: 9$ & $33: 17$ \\
\hline Age Range (years) & $42(35-65)$ & $37(22-67)$ \\
\hline Operative Time (min.) & $33.2 \pm 6.5(30-50)$ & $12.4 \pm 4.6(10-20)$ \\
\hline Hospital Stay (days) & $3.4 \pm 1.12(3$ to 5$)$ & $5.1 \pm 0.6$ \\
\hline Pain (VAS scale) Day 0 & $5.8 \pm 1.2$ & $3.3 \pm 0.8$ \\
\hline Day 1 & $4.1 \pm 0.8$ & $1.2 \pm 0.5$ \\
\hline Day 7 & $1.8 \pm 0.6$ & $22.4 \pm 6.12(20-30)$ \\
\hline Soaked Gauzes (mL) & $1.2 \pm 1.0(0-5)$ & 40 \\
\hline $\begin{array}{c}\text { Wound Healing Complete } \\
\text { By 3 weeks (\%) }\end{array}$ & 75 & 75 \\
\hline 4 weeks (\%) & 96 & $8.6 \pm 4.32(10-14)$ \\
\hline \multicolumn{2}{|c|}{ Table 1. Comparative details of both the Study Group Patients (n= 100) } \\
\hline
\end{tabular}

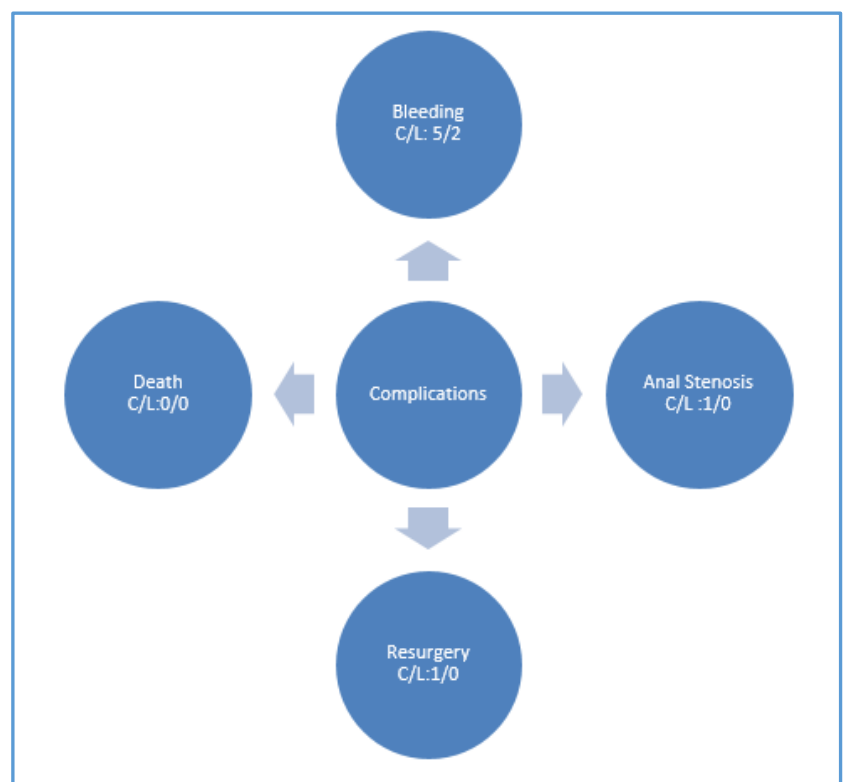

Figure 1. Comparative Complications of Conventional (C) and Ligasure (L) Methods

\section{DISCUSSION}

For Grade III and Grade IV internal haemorrhoids, the conventional methods like the Milligan-Morgan and the Ferguson's method have been the basic surgical practice and still remains the accepted modality of treatment. In the new era of surgery, there has been introduction of circular stapling device and Ligasure for prolapsed piles with relative merits and demerits. But the circular stapling device suffered with criticism for not treating the external component of haemorrhoids and the skin tags, (5) and to add on the stapler cartridges are bit expensive. With the introduction of Ligasure device,(6) an electrosurgical device an improved version of bipolar diathermy, haemorrhoid surgery has become more easy, a day care surgery with confidence to the surgeon as it is very effective in achieving haemostasis, moreover described as a 'vessel sealing system.' In the Ligasure device, the energy is delivered precisely only to the tissue which is grasped within the jaws of the hand piece with minimal spread of electrical or thermal injury to the adjacent tissues. Complete coagulation of vessels and also tissue is achieved with minimal charring in contrast to conventional diathermy with a computer controlled feedback loop, which automatically stops the flow of energy when coagulation of the vessels and mucosa is achieved.(7)
In a large meta-analysis of eleven trials on 1046 patients by Mastakov et al,(8) it was confirmed Ligasure haemorrhoidectomy to be effective, except for the overall incidence of complications which was not significant.

Altomare and the Italian Ligasure study group(9) in a prospective multicentric randomised trial on 273 patients showed a significant reduction in postoperative pain, a shorter operating time and a faster return to work, but no major difference in the incidence of post-operative bleeding and late complications upto 28 days after operation.

Milito et al(10) in a study on eleven randomised trials with a total of 850 patients reported a significant improvement in postoperative pain, wound healing and time off work, but no difference in postoperative bleeding and complications between the two groups.

Kwok et al (2005) showed that the Ligasure vessel sealing system allows complete coagulation of the blood vessels upto $7 \mathrm{~mm}$ in diameter, while confining the thermal spread to within $2 \mathrm{~mm}$ of adjacent tissue. The advantage of the same is extended to the excision of haemorrhoids, as it allows fast and bloodless dissection with minimal collateral damage. The study also confirms significant decrease in operative time and blood loss compared to diathermy patients. It was found that the patients with Ligasure had more pile mass excised than the patients in the diathermy group, which suggests that precise dissection is possible with Ligasure and better skin bridges can be preserved.(11)

In another study conducted by Wang J et al (2006), advantage of excising the external haemorrhoids along with the internal ones was seen. The mean operative time was less proving Ligasure a fast operating tool, the stay in the hospital was less concluding that it can be used as a day care surgery and patient's return to work was faster compensating for the expenditures of surgery. Further they concluded that Ligasure haemorrhoidectomy is associated with minimal complications, reduced anal spasm and is a very safe procedure. ${ }^{(12)}$

\section{CONCLUSION}

Ligasure haemorrhoidectomy with its numerous proven merits has the potential to make haemorrhoid surgery into a day care procedure. Essentially, the use of Ligasure is much easier, simpler and can be safely and effectively carried out by relatively inexperienced surgeons. In comparison to conventional haemorrhoidectomy, Ligasure haemorrhoidectomy has a shorter operating time, less blood loss, less pain score with less post-operative complications and reduced hospital stay and negligible incidence of residual 
haemorrhoids on follow-up. Even if the procedure is little costlier than the conventional one, it stands out superior to it as the procedure of choice for third and fourth degree haemorrhoids.

\section{ACKNOWLEDGEMENT}

A word of gratitude and thanks is conveyed to the Vice Chancellor and Principal of PMCH, Udaipur, for giving us the permission to carry out this study in the institution.

\section{REFERENCES}

[1] Shanmugam V, Thaha MA, Rabindranath KS, et al. Rubber band ligation versus excisional haemorrhoidectomy for haemorrhoids. Cochrane Database Syst Rev 2005;(3):CD005034.

[2] Milligan ETC, Morgan CN, Jones LE, et al. Surgical anatomy of the anal canal and the operative treatment of haemorrhoids. Lancet 1937;2:1119-24.

[3] Ferguson JA, Heaton JR. Closed hemorrhoidectomy. Dis Colon Rectum 1959;2(2):176-9.

[4] Jayaraman S, Colquhoun PH, Malthaner RA. Stapled versus conventional surgery for haemorrhoids. Cochrane Database Syst Rev 2006;(4):CD005393.

[5] Engel AF, Eijsbouts QA. Haemorrhoidectomy: painful choice. Lancet 2000;355(9222):2253-4.

[6] Sayfan J, Becker A, Koltun L. Sutureless closed haemorrhoidectomy: a new technique. Annals of Surgery 2001;234(1):21-4.
[7] Wang JY, Tsai HL, Chen FM, et al. Prospective, randomised, controlled trial of Starion ${ }^{\mathrm{TM}}$ vs Ligasure ${ }^{\mathrm{TM}}$ haemorrhoidectomy for prolapsed haemorrhoids. Dis Colon Rectum 2007;50(8):1146-51.

[8] Mastakov MY, Buettner PG, Ho YH. Updated metaanalysis of randomized controlled trials comparing conventional excisional haemorrhoidectomy with Ligasure for haemorrhoids. Techniques in Colpoproctology 2008;12(3):229-39.

[9] Altomare DF, Milito G, Andreoli R, et al. Ligasure precise vs. conventional diathermy for MilliganMorgan haemorrhoidectomy: a prospective, randomized, multicentre trial. Diseases of the Colon and Rectum 2008;51(5):514-9.

[10] Milito G, Cadeddu F, Muzi MG, et al. Haemorrhoidectomy with Ligasure vs. conventional excisional techniques: meta-analysis of randomized controlled trials. Colorectal Disease 2010;12(2):85-93.

[11] Kwok SY, Chung CC, Tsui KK, et al. A double -blind randomized trial comparing Ligasure ${ }^{\mathrm{TM}}$ and Harmonic Scalpel ${ }^{\mathrm{TM}}$ haemorrhoidectomy. Dis Colon Rectum 2005;48(2):344-8.

[12] Wang JY, Lu CY, Tsai HL, et al. Randomized controlled trial of Ligasure with sub mucosal dissection versus Ferguson haemorrhoidectomy for prolapsed haemorrhoids. World J Surg 2006;30(3):462-6. 